\title{
Impact of Ecklonia stolonifera extract on in vitro ruminal fermentation characteristics, methanogenesis, and microbial populations
}

\author{
Shin Ja Lee ${ }^{1, a}$, Jin Suk Jeong ${ }^{2, a}$, Nyeon Hak Shin ${ }^{3}$, Su Kyoung Lee ${ }^{4}$, Hyun Sang Kim \\ Jun Sik Eom ${ }^{5}$, and Sung Sill Lee ${ }^{1,2, *}$
}

\author{
* Corresponding Author: Sung Sill Lee \\ Tel: +82-55-772-1883, Fax: +82-55-772-1889, \\ E-mail: Iss@gnu.ac.kr \\ ${ }^{1}$ Institute of Agriculture and Life Science and \\ University-Centered Labs, Gyeongsang National \\ University, Jinju 52828, Korea \\ ${ }^{2}$ Division of Applied Life Science (BK21Plus) and \\ Institute of Agriculture and Life Science (IALS), \\ Gyeongsang National University, Jinju 52828, Korea \\ ${ }^{3}$ Livestock Experiment Station, Gyeongsangnamdo \\ Livestock Promotion Research Institute, Sancheong \\ 52733, Korea \\ ${ }^{4}$ Institute of Agriculture and Life Science, Gyeongsang \\ National University, Jinju 52828, Korea \\ ${ }^{5}$ Division of Applied Life Science (BK21Plus), \\ Gyeongsang National University, Jinju 52828, Korea \\ a These authors contributed equally to the work. \\ ORCID \\ Shin Ja Lee \\ https://orcid.org/0000-0002-4224-1211 \\ Jin Suk Jeong \\ https://orcid.org/0000-0001-6877-3067 \\ Nyeon Hak Shin \\ https://orcid.org/0000-0002-9069-0601 \\ Su Kyoung Lee \\ https://orcid.org/0000-0002-0997-2899 \\ Hyun Sang Kim \\ https://orcid.org/0000-0002-3422-1990 \\ Jun Sik Eom \\ https://orcid.org/0000-0001-5360-0147 \\ Sung Sill Lee \\ https://orcid.org/0000-0002-4621-4333
}

Submitted Feb 1, 2019; Revised Apr 8, 2019; Accepted May 16, 2019
Objective: This study was conducted to evaluate the effects of Ecklonia stolonifera (E. stolonifera) extract addition on in vitro ruminal fermentation characteristics, methanogenesis and microbial populations.

Methods: One cannulated Holstein cow $(450 \pm 30 \mathrm{~kg})$ consuming timothy hay and a commercial concentrate $(60: 40, \mathrm{w} / \mathrm{w})$ twice daily $(09: 00$ and $17: 00)$ at $2 \%$ of body weight with free access to water and mineral block were used as rumen fluid donors. In vitro fermentation experiment, with timothy hay as substrate, was conducted for up to $72 \mathrm{~h}$, with E. stolonifera extract added to achieve final concentration $1 \%, 3 \%$, and $5 \%$ on timothy hay basis.

Results: Administration of E. stolonifera extract to a ruminant fluid-artificial saliva mixture in vitro increased the total gas production. Unexpectedly, E. stolonifera extracts appeared to increase both methane emissions and hydrogen production, which is contrasts with previous observations with brown algae extracts used under in vitro fermentation conditions. Interestingly, real-time polymerase chain reaction indicated that as compared with the untreated control the ciliate-associated methanogen and Fibrobacter succinogenes populations decreased, whereas the Ruminococcus flavefaciens population increased as a result of E. stolonifera extract supplementation.

Conclusion: E. stolonifera showed no detrimental effect on rumen fermentation characteristics and microbial population. Through these results E. stolonifera has potential as a viable feed supplement to ruminants.

Keywords: Ecklonia stolonifera Extract; In vitro Fermentation; Methane Emission; Microbial Population

\section{INTRODUCTION}

Macro-algae are economically important and an under exploited plant resources, providing integral biomass for human foods and animal feed in recent years. Macro-algae-derived compounds have a broad range of biological activities such as antibiotic, antiviral, antioxidant, antifouling, anti-inflammatory, cytotoxic, anti-adipogenic, and antimitotic and thus confer potential health benefits [1]. In addition, macro-algae-derived compounds have been shown to increase growth rates and feed efficiency in ruminants [2]. However, they have counter-intuitively also been shown to impair fiber digestibility; thereby limiting diet digestibility [3].

Phaeophyta or brown algae are predominantly greenish brown in color due to the presence of the carotenoid fucoxanthin, and contain primary polysaccharides such as alginates, laminarins, fucans, and cellulose [4]. Ecklonia stolonifera (E. stolonifera) is a brown algae 
belonging to the Laminariaceae family that is commonly found in the sea forests off the coasts of Korea and Japan, growing on rocks near and below the low-tide mark on rough open coasts [5]. E. stolonifera has traditionally been utilized as an edible product and contains high levels of diverse phlorotannins, which are polymers of phloroglucinol found only in brown algae that have diverse biological activities, including anti-oxidative, antibacterial [5], and anti-inflammatory [6] properties. Moreover, E. stolonifera contains polyphenolic compounds that have been suggested to deter the grazing and growth of the seaweed's predators [7]. However, a few studies reported that algae have potential effect on rumen fermentation characteristics and methane reduction [8,9]. Identification of feed additives that can modify the rumen microbial system to manipulate ruminal fermentation characteristics and increase the efficiency of feed utilization is an effective strategy for inhibiting ruminal methanogenesis for reducing methane emissions without an adverse effect on rumen function.

To this end, we evaluated the potential effect of $E$. stolonifera on rumen fermentation using in vitro gas production technique. It has previously been applied to study the fermentation kinetics of feed composition. In addition, it can allow for the rapid screening of a large number of feed additives that may have effects on gas production [10].

Therefore, this study was conducted to evaluate effects of E. stolonifera extracts on in vitro ruminal fermentation, gas profile, and changes in microbial populations. These results could help to promote E. stolonifera as a natural alternative for improving ruminal fermentation.

\section{MATERIALS AND METHODS}

All experimental protocols were approved by the Animal Care and Use Committee of Gyeongsang National University (GNU180130-A0007, Jinju, Gyeongsangnam-do, Korea).

\section{Ecklonia stolonifera extract preparation}

E. stolonifera extract was obtained from the Jeju Biodiversity Research Institute (JBRI, Jeju, Korea). In brief, the plant material was washed and cut into small pieces, freeze-dried, and crushed. The plant powder was extracted with $80 \%$ methanol at room temperature $\left(20^{\circ} \mathrm{C}\right)$ using an ultrasonic cleaner (Branson Ultrasonics Corporation, Danbury, CT, USA). After extraction, the methanol eluate solutions were filtered through Whatman No. 1 filter (Whatman International Ltd, Maidstone, UK) paper and concentrated under a vacuum.

\section{In vitro fermentation design}

One cannulated Holstein cow $(450 \pm 30 \mathrm{~kg})$ was used as rumen fluid donors and provided with ad libitum access to a mineralvitamin block and water. Twice daily (09:00 and 17:00), cows were fed $2 \%$ of their body weight in timothy hay and com- mercial concentrate at a 60:40 (w/w) ratio. Rumen fluid was collected before morning feedings and filtered through four layers of cheesecloth. Next, it was diluted with artificial saliva and stored at $39^{\circ} \mathrm{C}$.

The chemical composition (\% dry matter [DM] basis) of commercial timothy hay was as follows: moisture content, $8.87 \%$; crude protein, $13.37 \%$; ether extracts, $2.25 \%$; crude fiber, $21.87 \%$; crude ash, $8.62 \%$; neutral detergent fiber, $53.18 \%$; and acid detergent fiber, $30.57 \%$.

The rumen fluid was mixed with McDougall's buffer in a 1:2 ratio. Next, $15 \mathrm{~mL}$ of the mixture was dispensed anaerobically into $50-\mathrm{mL}$ serum bottles containing $0.3 \mathrm{~g}$ of timothy for CON and E. stolonifera extract for treatments (TRTs) (3 $\mathrm{mg}$ for TRT1, $9 \mathrm{mg}$ for TRT2, $15 \mathrm{mg}$ for TRT3). The serum bottles were sealed anaerobically with an aluminum-capped butyl rubber stopper in pure $\mathrm{N}_{2}$ gas, and incubated in a shaking incubator (Jeio Tech, SI-900R, Daejeon, Korea; 120×rpm) at $39^{\circ} \mathrm{C}$ for $72 \mathrm{~h}$. The in vitro fermentation experiment was a completely randomized block design and performed in triplicate, using 60 serum bottles ( 4 treatments $\times 5$ incubation times $\times 3$ replicates times).

\section{Determination of gas profiles and ruminal fermentation characteristics}

Total gas production in the samples was measured with head space gas chromatography using a detachable pressure transducer and a digital readout voltmeter (Laurel Electronics, Inc., Costa Mesa, CA, USA). The transducer was connected to the inlet of a disposable Luer-lock three-way stopcock. Gas pressure in the headspace above the culture medium was read from the light emitting diode display unit after inserting a hypodermic syringe needle. Methane and carbon dioxide content was measured using a TCD detector with a Carboxen- 1006 Plot capillary column $(30 \mathrm{~mm} \times 0.53 \mathrm{~mm}$, Supelco, Bellefonte, PA, USA), after connecting another stopcock outlet to a gas chromatograph (HP 5890, Agilent Technologies, Santa Clara, CA, USA).

Next, serum bottles were uncapped, and the culture medium was subsampled for $\mathrm{pH}$ (MP230, Mettler-Toledo, Columbus, $\mathrm{OH}, \mathrm{USA}$ ), ammonia-N and volatile fatty acid (VFA) analyses. Ammonia-N concentration was measured as optical density (OD) values at $630 \mathrm{~nm}$ using a UV/VIS spectrophotometer (Model 680, Bio-Rad laboratories, Hercules, CA, USA). For VFA measurements, sub-samples were centrifuged at 3,000× rpm for $3 \mathrm{~min}$. The resultant supernatant was filtered using a $0.2 \mu \mathrm{m}$ disposable syringe filter (Whatman Inc., Clifton, NJ, USA) high performance liquid chromatography (Agilent1200, Waldbronn, Germany) using a UV/VIS detector with a MetaCarb $87 \mathrm{H}$ column $(300 \mathrm{~mm} \times 7.8 \mathrm{~mm}$, Varian, Palo Alto, CA, USA).

In vitro DM disappearance rate was determined following a modified Ørskov's method, using nylon-bag digestion. After 
incubation, the nylon bag containing serum bottles was washed twice in a water-bath equipped with a Heidolph Rotamax 120 (Heidolph Instruments, Nuremberg, Germany) at 100×rpm for $30 \mathrm{~min}$ and then oven dried at $60^{\circ} \mathrm{C}$ to a constant weight. The DM disappearance was the difference in serum-bottle weight before and after incubation.

\section{Microbial growth rate}

At the end of each fermentation period, samples were centrifuged at $3,000 \times \mathrm{rpm}$ for $3 \mathrm{~min}$ to remove feed particles. The supernatant was then re-centrifuged at $14,000 \times \mathrm{rpm}$ for $3 \mathrm{~min}$ to obtain a final supernatant for protein and glucose analysis. Some of the supernatant was dyed with Coomassie Blue G-250 for spectrophotometrically measuring protein content as OD at $595 \mathrm{~nm}$ (Model 680, Bio-Rad Laboratories, USA) [11]. For measuring glucose, $200 \mu \mathrm{L}$ of supernatant was mixed with $600 \mu \mathrm{L}$ of DNS solution and incubated for $5 \mathrm{~min}$ in a boiling water bath. Glucose concentration was the OD at $595 \mathrm{~nm}$, determined with a microplate reader (Model 680, Bio-Rad Laboratories, USA) [12]. Pellets from the centrifugation were washed with sodium phosphate buffer $(\mathrm{pH}$ 6.5) four more times and then subjected to OD measurements at $550 \mathrm{~nm}$ (Model 680, Bio-Rad Laboratories, USA) to evaluate microorganism growth rates.

\section{Quantitative polymerase chain reaction}

DNA was extracted from the incubated rumen samples using a QIAamp mini kit (QIAGEN, Valencia, CA, USA) according to the modified bead-beating protocol. Total nucleic acids were extracted by a high speed reciprocal shaker (TissueLyser; QIAGEN, USA), which retains the samples in screw-capped tubes containing ceramic and silica beads. In brief, $1 \mathrm{~mL}$ aliquots were taken from $15 \mathrm{~mL}$ of the incubated culture solution and centrifuged at 3,000 rpm for $5 \mathrm{~min} ; 1 \mu \mathrm{L}$ of the supernatant was used for nucleic acid concentration determination using a NanoDrop spectrophotometer (Thermo Scientific, Wilmington, DE, USA).
The polymerase chain reaction (PCR) primer sets were selected for amplification of general bacteria [13], ciliateassociated methanogens [14], methanogenic archaea [15], Fibrobacter succinogenes (F. succinogenes) [16], Ruminococcus albus (R. albus) [16], and Ruminococcus flavefaciens (R. flavefaciens) [16] as reported previously (Table 1).

Quantitative real-time PCR assays (CFX96 Real-Time system; Bio-Rad, USA) were conducted using the SYBR Green Supermix (QPK-201, Toyobo Co., Ltd., Tokyo, Japan) according to the methods described by Denman and McSweeney [13] and Denman et al [17]. The relative abundance of microbes was expressed according to the cycle threshold (Ct)

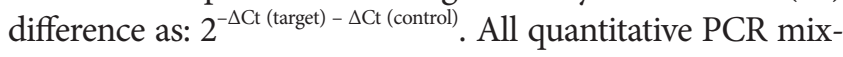
tures consisted of a $20 \mu \mathrm{L}$ volume, containing forward and reverse primers, DNA template, and DNA dye SYBR Green Supermix. The PCR amplification conditions for the target DNA, including the primer annealing and extension temperatures, were the same as those reported in the corresponding reference for each primer (Table 1).

\section{Statistical analysis}

All experimental data were analyzed using the general linear model procedure of SAS [18] as a completely randomized block design. The effects of supplementation of E. stolonifera extract on $\mathrm{pH}$, total gas production, DM disappearance, gas profiles, VFA profiles, and methanogen diversity were compared to those of the CON group, and the data were subjected to polynomial regression to measure the linear and quadratic effects of increasing concentrations of E. stolonifera. Variability in the data is expressed as the standard error of the mean; $p<0.05$ was considered to be statistically significant, whereas $\mathrm{p}<0.10$ was considered to indicate a tendency.

\section{RESULTS}

In vitro fermentation characteristics

E. stolonifera extract demonstrated improved cumulative gas

Table 1. Polymerase chain reaction primer sets for real-time polymerase chain reaction assays

\begin{tabular}{llc}
\hline Target species & Primer sequences $\left(\mathbf{5}^{\prime}\right.$ to $\left.\mathbf{3}^{\prime}\right)$ & Reference \\
\hline General bacteria & F: CGG CAA CGA GCG CAA CCC & {$[13]$} \\
Ciliate-associated methanogens & R: CCA TTG TAG CAC GTG TGT AGC C & {$[14]$} \\
Methanogenic archaea & F: AGG AAT TGG CGG GGG AGC AC & \\
Fibrobacter succinogenes & F: GGT GTG CAA GGA GCA GGG AC GTM GGA TTC ACA CAR TAY GCW ACA GC & {$[15]$} \\
Ruminococcus albus & R: TTC ATT GCR TAG TTW GGR TAG TT & {$[16]$} \\
Ruminococcus flavefaciens & F: GGT ATG GGA TGA GCT TGC & {$[16]$} \\
& F: CCC TAA AAG CAG TCT TAG TTC G CCC TGA ACT ATC & {$[16]$} \\
\hline
\end{tabular}


Table 2. Effect of Ecklonia stolonifera extracts on rumen fermentation characteristics

\begin{tabular}{|c|c|c|c|c|c|c|c|}
\hline \multirow{2}{*}{ Incubation time (h) } & \multicolumn{4}{|c|}{ Treatments $^{1)}$} & \multirow{2}{*}{ SEM } & \multicolumn{2}{|c|}{ Contrast } \\
\hline & CON & TRT1 & TRT2 & TRT3 & & Linear & Quadratic \\
\hline \multicolumn{8}{|l|}{ pH } \\
\hline 3 & 7.48 & 7.43 & 7.48 & 7.46 & 0.04 & 0.9938 & 0.6867 \\
\hline 12 & 7.32 & 7.25 & 7.33 & 7.28 & 0.03 & 0.8845 & 0.8023 \\
\hline 24 & 6.89 & 6.90 & 6.91 & 6.87 & 0.02 & 0.7286 & 0.2639 \\
\hline 48 & 6.63 & 6.67 & 6.64 & 6.59 & 0.03 & 0.3154 & 0.2283 \\
\hline 72 & 6.55 & 6.49 & 6.50 & 6.50 & 0.03 & 0.3132 & 0.3039 \\
\hline \multicolumn{8}{|c|}{ Gas production (mL/g DM) } \\
\hline 3 & 175.01 & 187.58 & 176.12 & 176.65 & 6.96 & 0.8386 & 0.4122 \\
\hline 12 & 191.38 & 204.53 & 188.48 & 205.64 & 11.79 & 0.6261 & 0.8691 \\
\hline 24 & $248.99^{b}$ & $252.53^{\mathrm{ab}}$ & $250.31^{b}$ & $259.23^{\mathrm{a}}$ & 2.31 & 0.0245 & 0.2764 \\
\hline 48 & $282.89^{b}$ & $288.11^{\mathrm{b}}$ & $289.38^{b}$ & $300.10^{\mathrm{a}}$ & 3.04 & 0.0046 & 0.3933 \\
\hline 72 & $288.85^{b}$ & $306.54^{\mathrm{a}}$ & $314.04^{\mathrm{a}}$ & $311.88^{\mathrm{a}}$ & 3.21 & 0.0007 & 0.0148 \\
\hline \multicolumn{8}{|l|}{ DM disappearance (\%) } \\
\hline 3 & 17.48 & 17.94 & 16.94 & 16.44 & 0.59 & 0.1595 & 0.4458 \\
\hline 12 & 17.83 & 19.03 & 20.07 & 20.34 & 1.96 & 0.3557 & 0.8163 \\
\hline 24 & $31.72^{\mathrm{ab}}$ & $29.14^{b}$ & $29.99^{\mathrm{ab}}$ & $32.52^{\mathrm{a}}$ & 0.97 & 0.4734 & 0.0299 \\
\hline 48 & 37.71 & 38.87 & 38.13 & 39.28 & 0.62 & 0.1911 & 0.9992 \\
\hline 72 & 41.34 & 41.99 & 41.55 & 41.62 & 0.37 & 0.8107 & 0.4616 \\
\hline
\end{tabular}

SEM, standard error of the mean; DM, dry matter.

1) Dietary treatments were as follows: CON, basal diet (without Ecklonia stolonifera extract); TRT 1, 1\% Ecklonia stolonifera; TRT 2, 3\% Ecklonia stolonifera; TRT 3, 5\% Ecklonia stolonifera on a substrate (timothy hay) basis.

$a, b$ Means with different superscripts in the same row indicate significant differences $(p<0.05)$.

production by mixed ruminal microorganisms as compared to that of the CON group (Table 2). However, there was no effect of E. stolonifera at different concentrations on $\mathrm{pH}$ and $\mathrm{DM}$ disappearance as compared with those of the CON group, except for an effect on DM disappearance at $24 \mathrm{~h}$ detected in the quadratic model.

As shown in Table 3, supplementation of E. stolonifera extract reduced the total levels of VFAs at $3 \mathrm{~h}$ and $48 \mathrm{~h}$, acetate at $48 \mathrm{~h}$, and butyrate at $3 \mathrm{~h}$. Overall, supplementation of $E$. stolonifera extract decreased the acetic acid-to propionic acid ratio (A/P ratio) at $48 \mathrm{~h}$ as compared with that of the $\mathrm{CON}$ group.

Lastly, supplementation of E. stolonifera extract increased the methane emissions at $3 \mathrm{~h}$ and $12 \mathrm{~h}$ (linear models only); hydrogen production at $3 \mathrm{~h}, 12 \mathrm{~h}$, and $72 \mathrm{~h}$; and ammonia production at $72 \mathrm{~h}$. By contrast, ammonia production was reduced at $24 \mathrm{~h}$, respectively, as compared to those of the CON group (Table 4 ).

\section{Change in ruminal microbial diversity}

E. stolonifera extract increased the microbial growth rate at $48 \mathrm{~h}$ and the glucose concentration at $3 \mathrm{~h}$, while reducing the protein concentration at $12 \mathrm{~h}$ and at $24 \mathrm{~h}$ as compared with those of the CON group (Table 5).

The ciliate-associated methanogen and methanogenic archaea populations were reduced at $12 \mathrm{~h}(\mathrm{p}<0.0001)$ and $24 \mathrm{~h}$ $(\mathrm{p}=0.0164)$ following supplementation with various con- centrations of E. stolonifera extract as compared with those of the CON group. In addition, E. stolonifera extract reduced the abundance of the major fibrolytic microorganisms such as F. succinogenes at $12 \mathrm{~h}(\mathrm{p}=0.0113)$ and $24 \mathrm{~h}(\mathrm{p}=0.0145)$. The proportion of $R$. flavefaciens increased at $12 \mathrm{~h}$ of incubation with $E$. stolonifera extract $(\mathrm{p}=0.0001)$, whereas the $R$. albus population remained unchanged or slightly increased as compared with that of the CON group (Figure 1).

\section{DISCUSSION}

Denis et al [19] reported that algae contain candidate compounds with potential to assist in ruminants feeding for improved gas production and fermentation management, within the context of dietary fiber provision. In this study, dietary fiber, as determined through the dose response of E. stolonifera, induced an increase in total gas production without any accompanying change in DM loss. DM disappearance only showed an effect with the addition of $1 \%, 3 \%$, and $5 \%$ E. stolonifera extract at $24 \mathrm{~h}$ incubation, whereas the total gas production under all levels of $E$. stolonifera extract was higher as compared to that under incubation with Timothy hay alone at 24,48 , and $72 \mathrm{~h}$, indicating the potential of this extract for improved feed efficiency [20]. The $\mathrm{pH}$ also remained consistent in the range of 6.49 to 7.48 for all doses of E. stolonifera applied during microbial fermentation, suggesting that ruminal microbial activity was not negatively 
Table 3. Effect of Ecklonia stolonifera extracts on VFA by mixed rumen microbial fermentation

\begin{tabular}{|c|c|c|c|c|c|c|c|}
\hline \multirow{2}{*}{ Incubation time (h) } & \multicolumn{4}{|c|}{ Treatments $^{1)}$} & \multirow{2}{*}{ SEM } & \multicolumn{2}{|c|}{ Contrast } \\
\hline & CON & TRT 1 & TRT 2 & TRT 3 & & Linear & Quadratic \\
\hline \multicolumn{8}{|c|}{ Total VFA concentration $(\mathrm{mM} / \mathrm{g})$} \\
\hline 3 & $72.00^{\mathrm{ab}}$ & $81.08^{\mathrm{a}}$ & $67.62^{b}$ & $65.35^{b}$ & 2.85 & 0.0305 & 0.0814 \\
\hline 12 & 79.12 & 88.59 & 79.13 & 79.05 & 4.04 & 0.6079 & 0.2714 \\
\hline 24 & 101.92 & 96.37 & 88.34 & 88.23 & 10.06 & 0.3069 & 0.7936 \\
\hline 48 & $118.93^{\mathrm{a}}$ & $102.76^{b}$ & $95.56^{b}$ & $100.16^{b}$ & 4.44 & 0.0127 & 0.0477 \\
\hline 72 & 189.75 & 178.98 & 191.12 & 202.28 & 22.52 & 0.6347 & 0.6393 \\
\hline \multicolumn{8}{|c|}{ Acetic acid concentration (mM/g) } \\
\hline 3 & 51.63 & 59.29 & 49.26 & 47.29 & 2.77 & 0.1000 & 0.1204 \\
\hline 12 & 57.94 & 64.03 & 56.69 & 55.60 & 3.06 & 0.3241 & 0.2740 \\
\hline 24 & 73.81 & 68.96 & 61.40 & 59.25 & 9.49 & 0.2619 & 0.8903 \\
\hline 48 & $85.77^{\mathrm{a}}$ & $71.11^{b}$ & $61.79^{b}$ & $67.27^{b}$ & 3.54 & 0.0035 & 0.0218 \\
\hline 72 & 153.63 & 142.62 & 153.83 & 165.37 & 22.82 & 0.6613 & 0.6344 \\
\hline \multicolumn{8}{|c|}{ Propionic acid concentration (mM/g) } \\
\hline 3 & 11.27 & 13.92 & 11.22 & 10.80 & 2.08 & 0.6705 & 0.4808 \\
\hline 12 & 11.72 & 15.55 & 13.06 & 13.88 & 1.74 & 0.6222 & 0.4129 \\
\hline 24 & 18.55 & 18.34 & 16.41 & 19.28 & 0.95 & 0.9536 & 0.1441 \\
\hline 48 & 22.13 & 21.98 & 21.86 & 21.81 & 1.36 & 0.8631 & 0.9670 \\
\hline 72 & 24.72 & 25.07 & 24.57 & 25.03 & 0.60 & 0.8713 & 0.9336 \\
\hline \multicolumn{8}{|c|}{ Butyric acid concentration $(\mathrm{mM} / \mathrm{g})$} \\
\hline 3 & $4.55^{\mathrm{a}}$ & $3.94^{b}$ & $3.57^{b}$ & $3.63^{b}$ & 1.36 & 0.0016 & 0.0555 \\
\hline 12 & 4.73 & 4.50 & 4.69 & 4.79 & 0.76 & 0.8562 & 0.7160 \\
\hline 24 & 4.78 & 4.54 & 5.27 & 4.85 & 0.51 & 0.8139 & 0.9251 \\
\hline 48 & 5.51 & 4.84 & 5.96 & 5.54 & 0.20 & 0.7575 & 0.8815 \\
\hline 72 & 5.70 & 5.64 & 6.36 & 5.94 & 0.99 & 0.6516 & 0.7975 \\
\hline \multicolumn{8}{|l|}{ A/P ratio } \\
\hline 3 & 5.39 & 4.27 & 4.98 & 4.94 & 0.73 & 0.9177 & 0.6993 \\
\hline 12 & 5.63 & 4.12 & 4.50 & 4.01 & 0.69 & 0.2236 & 0.5216 \\
\hline 24 & 3.98 & 3.75 & 3.81 & 3.07 & 0.57 & 0.2803 & 0.6290 \\
\hline 48 & $3.89^{\mathrm{a}}$ & $3.24^{\mathrm{ab}}$ & $2.86^{b}$ & $3.09^{b}$ & 0.60 & 0.0150 & 0.0607 \\
\hline 72 & 6.24 & 5.74 & 6.26 & 6.62 & 0.96 & 0.7152 & 0.6738 \\
\hline
\end{tabular}

VFA, volatile fatty acids; SEM, standard error of the mean; A/P ratio, acetate to propionate acid ratio.

1) Dietary treatments were as follows: CON, basal diet (without Ecklonia stolonifera extract); TRT 1, 1\% Ecklonia stolonifera; TRT 2, 3\% Ecklonia stolonifera; TRT 3, 5\% Ecklonia stolonifera on a substrate (timothy hay) basis.

$a, b$ Means with different superscripts in the same row indicate significant differences $(p<0.05)$.

affected since it was greater than the minimal $\mathrm{pH}$ of 5.0 to $5.5[21]$.

By contrast, Wang et al [3] and Dubois et al [20] reported that brown algae species resulted in lower gas production than that of the control sample during in vitro ruminal fermentation. Therefore, some bioactive compounds of certain brown algae species might reduce the utilization of nutrients, thereby directly inhibiting microbial activity or indirectly by forming complexes with the nutrients [22]. Interestingly, the E. stolonifera extract caused a decrease in the total VFA and acetate concentrations, and resulted in a lower $\mathrm{A} / \mathrm{P}$ ratio than those of the $\mathrm{CON}$ group at $48 \mathrm{~h}$ incubation, demonstrating that fermentation was affected. Secondary metabolites from E. stolonifera extracts have been reported to contain phlorotannins and polyphenolic compounds, which have strong antimicrobial properties and can deter the growth of the seaweed's preda- tors [7]. Thus, it is possible that these secondary metabolites may have induced a reduction in the total VFA concentration and altered the acetate and propionate concentrations, which are common characteristics often associated with antinutritional factors that interfere with ruminal fermentation [23].

With regards to emission gases, E. stolonifera extracts appeared to increase the in vitro methane emissions, and hydrogen and ammonia production, while carbon dioxide production did not increase under in vitro ruminal fermentation. As such, these results do not demonstrate a clear consensus trend, given that a mixed outcome was observed under different conditions. Rumen ammonia production may vary depending on the proportion of feed protein and the degradation rate; therefore, it was difficult to observe any difference in ammonia production except at $24 \mathrm{~h}$ and $72 \mathrm{~h}$ of fermentation, since 
Table 4. Effect of Ecklonia stolonifera extracts on in vitro gas and ammonia production by mixed rumen fermentation

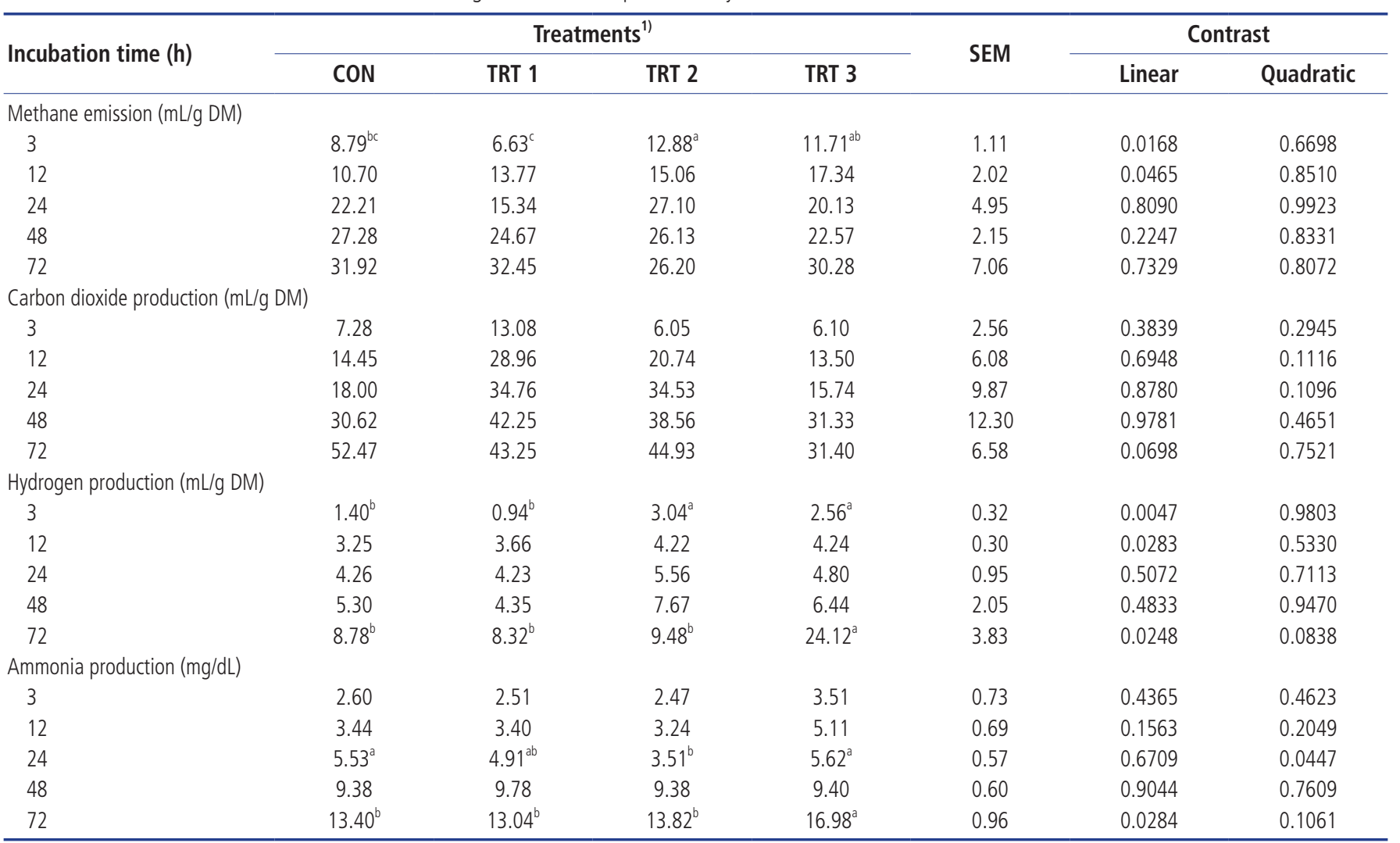

SEM, standard error of the mean; DM, dry matter.

1) Dietary treatments were as follows: CON, basal diet (without Ecklonia stolonifera extract); TRT 1, 1\% Ecklonia stolonifera; TRT 2, 3\% Ecklonia stolonifera; TRT 3, 5\% Ecklonia stolonifera on a substrate (timothy hay) basis.

${ }^{a-c}$ Means with different superscripts in the same row indicate significant differences $(p<0.05)$.

Table 5. Effect of Ecklonia stolonifera extracts on rumen microbial growth rate, protein and glucose concentration

\begin{tabular}{|c|c|c|c|c|c|c|c|}
\hline \multirow{2}{*}{ Incubation (h) } & \multicolumn{4}{|c|}{ Treatments $^{1)}$} & \multirow{2}{*}{ SEM } & \multicolumn{2}{|c|}{ Contrast } \\
\hline & CON & TRT 1 & TRT 2 & TRT 3 & & Linear & Quadratic \\
\hline \multicolumn{8}{|c|}{ Microbial growth rate (OD at $550 \mathrm{~nm})$} \\
\hline 12 & 0.35 & 0.31 & 0.36 & 0.30 & 0.02 & 0.4335 & 0.5646 \\
\hline 24 & 0.28 & 0.32 & 0.28 & 0.28 & 0.03 & 0.8478 & 0.5006 \\
\hline 48 & $0.32^{b}$ & $0.38^{\mathrm{ab}}$ & $0.37^{\mathrm{ab}}$ & $0.43^{\mathrm{a}}$ & 0.03 & 0.0295 & 1.0000 \\
\hline 3 & 0.14 & 0.16 & 0.15 & 0.15 & 0.01 & 0.5664 & 0.5868 \\
\hline 12 & $0.19^{\mathrm{a}}$ & $0.16^{\mathrm{b}}$ & $0.15^{b}$ & $0.16^{b}$ & 0.01 & 0.0323 & 0.0490 \\
\hline 24 & $0.24^{\mathrm{a}}$ & $0.19^{b}$ & $0.18^{\mathrm{b}}$ & $0.19^{b}$ & 0.01 & 0.0017 & 0.0089 \\
\hline 48 & 0.27 & 0.20 & 0.18 & 0.21 & 0.03 & 0.2304 & 0.1758 \\
\hline 72 & 0.28 & 0.23 & 0.23 & 0.23 & 0.04 & 0.4818 & 0.6027 \\
\hline 48 & 0.17 & 0.15 & 0.16 & 0.16 & 0.03 & 0.9801 & 0.7620 \\
\hline 72 & 0.34 & 0.19 & 0.31 & 0.27 & 0.13 & 0.8968 & 0.6775 \\
\hline
\end{tabular}

SEM, standard error of the mean; OD, optical density.

1) Dietary treatments were as follows: CON, basal diet (without Ecklonia stolonifera extract); TRT 1, 1\% Ecklonia stolonifera; TRT 2, 3\% Ecklonia stolonifera; TRT 3, 5\% Ecklonia stolonifera on a substrate (timothy hay) basis.

$a, b$ Means with different superscripts in the same row indicate significant differences $(p<0.05)$. 
(a)

RT-PCR

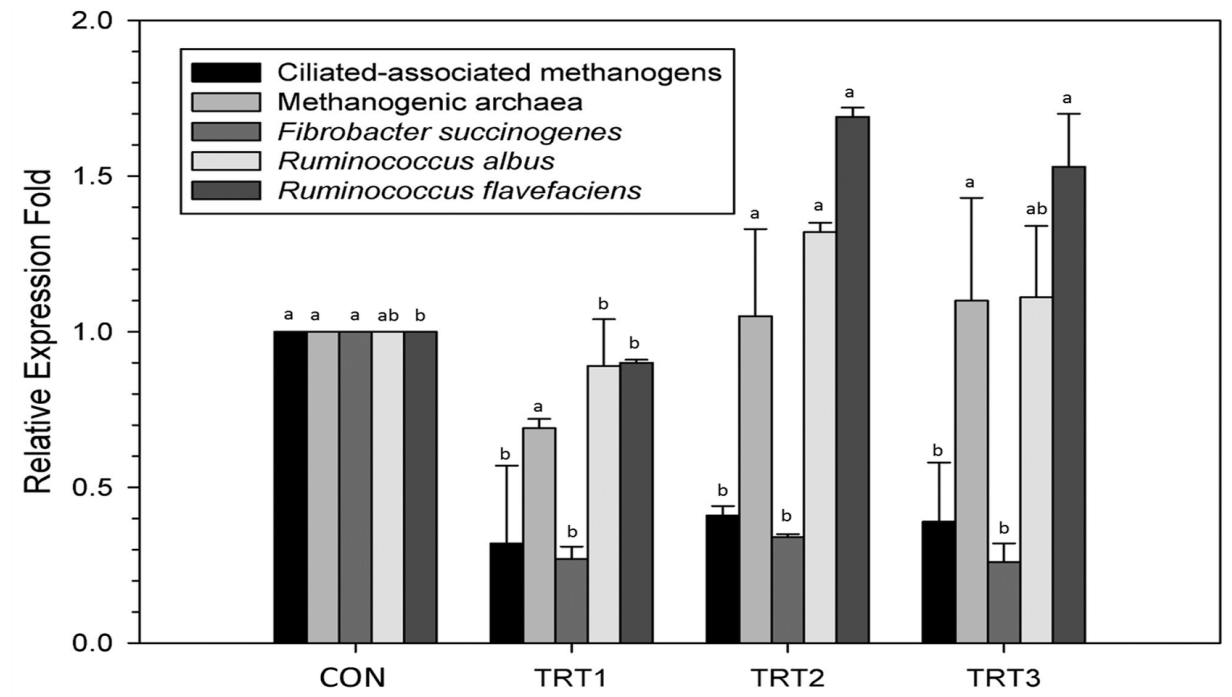

(b)

RT-PCR

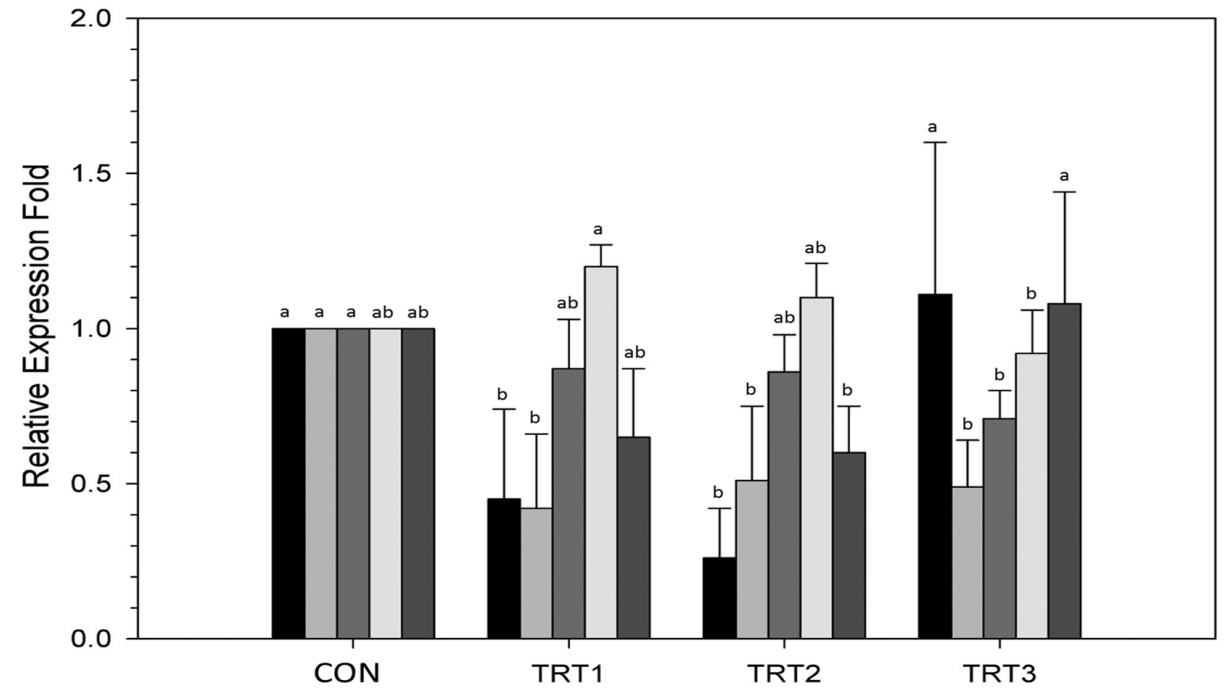

Figure 1. Relative quantification of rumen microorganism populations under in vitro ruminal fermentation for (a) $12 \mathrm{~h}$ and (b) $24 \mathrm{~h}$. Dietary treatments were as follows: CON, basal diet (without Ecklonia stolonifera extract); TRT 1, 1\% Ecklonia stolonifera; TRT 2, 3\% Ecklonia stolonifera; TRT 3, 5\% Ecklonia stolonifera, on a substrate (timothy hay) basis. ${ }^{a, b}$ Means with different superscripts in the same row indicate significant differences $(p<0.05)$.

timothy hay was the only substrate utilized. Wang et al [3] and Machado et al [23] reported a reduction of methane emissions when experimenting with brown algae extracts under in vitro fermentation conditions. Brown algae species generally show the ability to reduce methane emissions, which is most likely attributed to their phlorotannins and a range of other natural products [22,24]. However, the results from our study are in disagree with those of Wang et al [3] and Machado et al [23] as the E. stolonifera extracts appeared to actually increase methane emissions and hydrogen production at $3 \mathrm{~h}$. This finding is in line with the results of Mitsumori and Sun [25], who suggested that ruminal methanogens utilizing mainly hydrogen would be the main source of an increase in methane emissions.
The effects of E. stolonifera on microbial diversity also initially appeared to be counter intuitive with the observed increase in methane and hydrogen production. E. stolonifera extracts reduced the populations of the ciliate-associated methanogens, methanogenic archaea, and F. succinogenes, while increasing the $R$. flavefaciens population as compared with those of the CON group. However, the R. albus population was left unchanged. Ciliate-associated methanogens may generate up to $37 \%$ of the methane produced in the rumen [26], and most methanogenic archaea can reduce $\mathrm{CO}_{2}$ with $\mathrm{H}_{2}$ to produce methane [27]. However, F. succinogenes is a non- $\mathrm{H}_{2}$-producing species [28]. Therefore, given the major reduction in the ciliate-associated methanogens and methanogenic archaea populations, a consequent reduction in methane 
production would be expected; however, this was not the case. $R$. albus and $R$. flavefaciens are two of the three major members of the fibrolytic microorganism population, the third being F. succinogenes. $R$. albus has shown great promise in the production of $\mathrm{H}_{2}$ from energy forage, with potential for utilizing cellulosic and hemicellulosic biomass [29]. In addition, $R$. flavefaciens normally produces succinic acid as a major fermentation product together with acetic and formic acids, $\mathrm{H}_{2}$, and $\mathrm{CO}_{2}$ [30]. As such, the increase in the $R$. flavefaciens population along with the unchanged $R$. albus population may have contributed to the observed increase in hydrogen production. Therefore, even with reductions in the ciliate-associated methanogens and methanogenic archaea populations, the increase in hydrogen availability may have allowed for increased methane emissions. Chaucheyras-Durand et al [28] showed that methane emissions clearly reduced when the dominant fibrolytic species was a non- $\mathrm{H}_{2}$-producing species such as F. succinogenes, without significantly impairing fiber degradation and fermentation in the rumen. This suggests that $\mathrm{H}_{2}$ is the critical factor for the microbial ecosystem in ruminants. The $\mathrm{H}_{2}$ produced during enteric fermentation is the precursor of methane emissions from ruminants, and thus the regulation of $\mathrm{H}_{2}$, rather than methane appears to be the key to controlling ruminant methane emissions.

Lastly, the E. stolonifera extract doses that led to higher microbial growth rates also caused higher total gas production as compared to the CON group; therefore, the rumen microorganism growth rate appears to be closely related to the total gas production and fermentation process, as suggested by Hungate [31]. In particular, the E. stolonifera extracts significantly increased microbial growth at $48 \mathrm{~h}$ as compared to that of the CON group. Moreover, our results confirmed that rumen fermentation with $E$. stolonifera extracts did not result in any negative side effects on protein or glucose concentrations throughout the experimental period. In fact, E. stolonifera extracts appeared to reduce the protein concentration at 12 $\mathrm{h}$ and $24 \mathrm{~h}$. However, the protein concentration does not appear to be correlated with ammonia concentration, as Mehrez et al [32] reported that the optimal ammonia concentration could lead to maximal protein synthesis by microorganisms.

In conclusion, we demonstrated the effects of $E$. stolonifera on in vitro ruminant fermentation characteristics. E. stolonifera extracts also appear to be capable of mitigating a series of effects throughout the period of in vitro rumen fermentation, some of which may not be desirable. For example, E. stolonifera extracts could increase methane emissions and hydrogen production, which disagrees with previous observations on brown algae extracts under in vitro fermentation conditions. However, the changes in ruminal microbial diversity were able to partially explain the observed increase in methane and hydrogen observed with treatment of E. stolonifera extracts. More research is required to elucidate the potential of E. stolonifera for improving growth performance and methane emissions of ruminants.

\section{CONFLICT OF INTEREST}

We certify that there is no conflict of interest with any financial organization regarding the material discussed in the manuscript.

\section{ACKNOWLEDGMENTS}

This work was supported by the National Foundation of Korea Grant funded by the Korean Government (NRF-2015R1A 6A1A03031413). Jin Suk Jeong was supported by Postdoctoral Fellowship from the BK21Plus Program, the Ministry of Education, Science and Technology, Republic of Korea. This work was presented as a part of a doctoral dissertation by Nyeon Hak Shin.

\section{REFERENCES}

1. Jung HA, Jung HJ, Jeong HY, Kwon HJ, Ali MY, Choi JS. Phlorotannins isolated from the edible brown alga Ecklonia stolonifera exert anti-adipogenic activity on 3T3-L1 adipocytes by downregulating C/EBPa and PPAR $\gamma$. Fitoterapia 2014;92: 260-9. https://doi.org/10.1016/j.fitote.2013.12.003

2. Chowdhury S, Huque K, Khatun M. Algae in animal production. Agracultural Science of Biodiversity and Sustainability Workshop, Tune Landboskole, Denmark; 1995. pp. 181-91.

3. Wang Y, Xu Z, Bach SJ, McAllister TA. Effects of phlorotannins from Ascophyllum nodosum (brown seaweed) on in vitro ruminal digestion of mixed forage or barley grain. Anim Feed Sci Technol 2008;145:375-95. https://doi.org/10.1016/ j.anifeedsci.2007.03.013

4. Haugan JA, Liaaenjensen S. Algal Carotenoids 54. Carotenoids of brown algae (Phaeophyceae). Biochem Syst Ecol 1994;22: 31-41. https://doi.org/10.1016/0305-1978(94)90112-0

5. Kuda T, Kunii T, Goto H, Suzuki T, Yano T. Varieties of antioxidant and antibacterial properties of Ecklonia stolonifera and Ecklonia kurome products harvested and processed in the Noto peninsula, Japan. Food Chem 2007;103:900-5. https:// doi.org/10.1016/j.foodchem.2006.09.042

6. Kim S, Wijesekara I. Development and biological activities of marine-derived bioactive peptides: a review. J Funct Foods 2010;2:1-9. https://doi.org/10.1016/j.jff.2010.01.003

7. Winter FC, Estes JA. Experimental evidence for the effects of polyphenolic compounds from Dictyoneurum californicum Ruprecht (Phaeophyta: Laminariales) on feeding rate and growth in the red abalone Haliotus rufescens Swainson. J Exp Mar Biol Ecol 1992;155:263-77. https://doi.org/10.1016/00220981(92)90067-K

8. Lee SJ, Shin NH, Jeong JS, Kim ET, Lee SK, Lee SS. Effect of 
Rhodophyta extracts on in vitro ruminal fermentation characteristics, methanogenesis and microbial populations. AsianAustralas J Anim Sci 2018;31:54-62. https://doi.org/10.5713/ ajas.17.0620

9. Lee SJ, Shin NH, Jeong JS, et al. Effects of Gelidium amansii extracts on in vitro ruminal fermentation characteristics, methanogenesis, and microbial populations. Asian-Australas J Anim Sci 2018;31:71-9. https://doi.org/10.5713/ajas.17.0619

10. Pellikaan WF, Hendriks WH, Uwimana G, Bongers LJGM, Becker PM, Cone JW. A novel method to determine simultaneously methane production during in vitro gas production using fully automated equipment. Anim Feed Sci Technol 2011;168:196-205. https://doi.org/10.1016/j.anifeedsci.2011. 04.096

11. Bradford MM. A rapid and sensitive method for the quantitation of microgram quantities of protein utilizing the principle of protein-dye binding. Anal Biochem 1976;72:248-54. https:// doi.org/10.1016/0003-2697(76)90527-3

12. Miller GL. Use of dinitrosalicylic acid reagent for determination of reducing sugar. Anal Biochem 1959;31:426-8. https:// doi.org/10.1021/ac60147a030

13. Denman SE, McSweeney CS. Development of a real-time PCR assay for monitoring anaerobic fungal and cellulolytic bacterial populations within the rumen. FEMS Microbiol Ecol 2006; 58:572-82. https://doi.org/10.1111/j.1574-6941.2006.00190.x

14. Luton PE, Wayne JM, Sharp RJ, Riley PW. The $m c r A$ gene as an alternative to $16 \mathrm{~S}$ rRNA in the phylogenetic analysis of methanogen populations in landfill. Microbiology 2002;148: 3521-30. https://doi.org/10.1099/00221287-148-11-3521

15. Tajima K, Nagamine T, Matsui H, Nakamura M, Aminov RI. Phylogenetic analysis of archaeal 16S rRNA libraries from the rumen suggests the existence of a novel group of archaea not associated with known methanogens. FEMS Microbiol Lett 2001;200:67-72. https://doi.org/10.1111/j.1574-6968.2001. tb10694.x

16. Koike S, Kobayashi Y. Development and use of competitive PCR assays for the rumen cellulolytic bacteria: Fibrobacter succinogenes, Ruminococcus albus and Ruminococcus flavefaciens. FEMS Microbiol Lett 2001;204:361-6. https://doi. org/10.1111/j.1574-6968.2001.tb10911.x

17. Denman SE, Tomkins NW, McSweeney CS. Quantitation and diversity analysis of ruminal methanogenic populations in response to the antimethanogenic compound bromochloromethane. FEMS Microbiol Ecol 2007;62:313-22. https:// doi.org/10.1111/j.1574-6941.2007.00394.x

18. SAS Institute Inc. SAS/STAT user's guide: Version 9.2 edn. Cary, NC, USA: SAS Institute Inc.; 2002.

19. Denis C, Morançais M, Li M, et al. Study of the chemical composition of edible red macroalgae Grateloupia turuturu from Brittany (France). Food Chem 2010;119:913-7. https:// doi.org/10.1016/j.foodchem.2009.07.047
20. Dubois B, Tomkins NW, Kinley RD, et al. Effect of tropical algae as additives on rumen in vitro gas production and fermentation characteristics. Am J Plant Sci 2013;4:34-43. https:// doi.org/10.4236/ajps.2013.412A2005

21. Hoover WH. Chemical factors involved in ruminal fiber digestion. J Dairy Sci 1986;69:2755-66. https://doi.org/10.3168/ jds.S0022-0302(86)80724-X

22. Min BR, Barry TN, Attwood GT, Mc-Nabb WC. The Effect of condensed tannins on the nutrition and health of ruminants fed fresh temperate forages: a review. Anim Feed Sci Technol 2003;106:3-19. https://doi.org/10.1016/S0377-8401 (03)00041-5

23. Machado L, Magnusson M, Paul NA, de Nys R, Tomkins N. Effects of marine and freshwater macroalgae on in vitro total gas and methane production. PLoS One 2014;9:e85289. https:// doi.org/10.1371/journal.pone.0085289

24. Gupta S, Abu-Ghannam N. Bioactive potential and possible health effects of edible brown seaweeds. Trends Food Sci Technol 2011;22:315-26. https://doi.org/10.1016/j.tifs.2011. 03.011

25. Mitsumori M, Sun W. Control of rumen microbial fermentation for mitigating methane emissions from the rumen. Asian-Australas J Anim Sci 2008;21:144-54. https://doi.org/ 10.5713/ajas.2008.r01

26. Finlay BJ, Esteban G, Clarke KJ, et al. Some rumen ciliates have endosymbiotic methanogens. FEMS Microbiol Lett 1994; 117:157-61.

27. Thauer RK, Kaster AK, Seedorf H, Buckel W, Hedderich R. Methanogenic archaea: ecologically relevant differences in energy conservation. Nat Rev Microbiol 2008;6:579-91. https:// doi.org/10.1038/nrmicro1931

28. Chaucheyras-Durand F, Masséglia S, Fonty G, Forano E. Influence of the composition of the cellulolytic flora on the development of hydrogenotrophic microorganisms, hydrogen utilization, and methane production in the rumens of gnotobiotically reared lambs. Appl Environ Microbiol 2010;76: 7931-7. https://doi.org/10.1128/AEM.01784-10

29. Ntaikou I, Gavala HN, Kornaros M, Lyberatos G. Hydrogen production from sugars and sweet sorghum biomass using Ruminococcus albus. Int J Hydrogen Energy 2008;33:115363. https://doi.org/10.1016/j.ijhydene.2007.10.053

30. Latham MJ, Wolin MJ. Fermentation of cellulose by Ruminococcus flavefaciens in the presence and absence of Methanobacterium ruminantium. Appl Environ Microbiol 1977;34: 297-301.

31. Hungate RE. The rumen and it's microbes. NY, USA: Academic Press; 1966. pp. 92-446.

32. Mehrez AZ, Ørskov ER, Mcdonald I. Rates of rumen fermentation in relation to ammonia concentration. Br J Nutr 1977; 38:437-43. https://doi.org/10.1079/BJN19770108 